\title{
Plantas de cobertura em sucessão ao milho para silagem em condições do cerrado
}

\section{Cover crops in succession to corn for silage in cerrado conditions}

Gustavo Franco de Castro ${ }^{1, *}$ (D) , Carine Gregório Machado Silva ${ }^{2,(D)}$, Silvino Guimarães Moreira 2, (D) , Álvaro Vilela de Resende $^{3, \text { iD }}$

${ }^{1}$ Universidade Federal de Viçosa (UFV). Campus Universitário. CEP 36570900. Viçosa-MG, Brasi

${ }^{2}$ Universidade Federal de Lavras (UFLA). Departamento de Agricultura. CEP 37200000. Lavras-MG, Brasil.

${ }^{3}$ Empresa Brasileira de Pesquisa Agropecuária (EMBRAPA MILHO E SORGO). Cx. Postal 285, Rodovia MG 424, Km 45. CEP 35701970. Sete Lagoas-MG, Brasil.

*Autor para correspondência: gustavofcastro@ymail.com

\section{RESUMO}

OPPEN ACESS

Informações adicionais

Recebido: 19/11/2016

Aceito: 22/01/2017

Publicado: 15/04/2017

Editor:

Vinicius Batista Campos Instituto Federal do Amapá, Macapá, AP.

vinicius.campos@ifap.edu.br

\section{Revisão por pares às cegas}

Processos de revisão

Prot. 1302016R01 (Brasil)

Prot. 1302016R02 (Brasil)

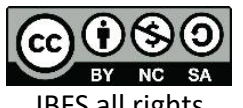

Copyright: (C) 2017
Embora tenham sido desenvolvidos alguns estudos nos últimos anos com plantas de cobertura em áreas de produção de grãos, informações sobre espécies de cobertura em sucessão ao milho para silagem ainda são escassas. O objetivo deste trabalho foi avaliar o efeito de diferentes plantas de cobertura no acúmulo de nutrientes e produtividade de massa seca (MS) na parte aérea das plantas de milho, em área de produção de silagem, na região central de Minas Gerais. O experimento foi conduzido nas safras de 2012/2013 e 2013/2014, empregando-se oito tratamentos constituídos por seis espécies de cobertura (nabo forrageiro, milheto, braquiária ruzziziensis, braquiáira decumbens, crotalária e girassol), um tratamento composto pela mistura das espécies milheto e crotalária e uma área de pousio, como controle. O experimento foi montado em delineamento experimental, em blocos casualizados, com quatro repetições. Nos dois anos de cultivo, as quantidades totais dos nutrientes acumulados na parte aérea das plantas de milho não variaram com as plantas de cobertura, com exceção da quantidade de Fe. Nas duas safras, a produtividade de MS da parte aérea do milho não variou em função das diferentes plantas de cobertura. A ausência de resposta na produtividade de milho foi atribuída à falta de umidade adequada para o cultivo do milho, devido aos veranicos ocorridos durante as safras.

Palavras-chave: Espécies de cobertura. Plantio direto. Semeadura direta. Produção de silagem.

\section{ABSTRACT}

Although some studies on cover crops in grain production areas have been developed in recent years, information on cover crops in succession to corn silage are still scarce. The objective of this study was to evaluate the effect of different cover crops on the accumulation of nutrients and dry mass yield (DM) in shoots of corn plants in silage production area in the central region of Minas Gerais. The experiment was carried out in two different harvests: 2012/2013 and 2013/2014, which eigth treatments were used consisted of six cover species (turnip, millet, B. ruzziziensis, B. decumbens, crotalaria and sunflower), in addition to a treatment comprising the mixture of millet and crotalaria species and fallow area representing control treatment. The experiment was conducted in a randomized block design with four replications. In the two years of cultivation, the total quantities of nutrients accumulated in the shoots of corn plants did not vary with cover crops, except for the amount of Fe. In two crops, DM yield of corn shoots did not vary according to the different cover crops. The absence of response in corn yield was attributed to lack of adequate moisture for growing corn due to dry spells during harvests.

Keywords: Cover species. Tillage. Direct seeding. Silage production. 


\section{INTRODUÇÃO}

O Estado de Minas Gerais é o principal produtor de leite do Brasil e, para manter seu rebanho no período seco do ano, utiliza a silagem de planta inteira de milho como principal forragem. Não há estatísticas oficiais quanto à área cultivada com milho silagem, produção e/ou evolução das produtividades ao longo dos anos (Moreira et al., 2014). No entanto, tem havido ganhos de produtividade nas áreas com utilização de cultivares modernas, culturas de inverno e rotação de culturas, após a consolidação do sistema de semeadura direta (SSD).

O SSD tem sido considerado uma importante estratégia para melhorar a segurança alimentar, através do aumento da produtividade das culturas e da redução da degradação dos recursos ambientais (FAO, 2012). Porém, apesar de o país apresentar uma grande área sob esse sistema, cerca de 32 milhões de hectares (Federação Brasileira de Plantio direto na Palha - FEBRAPDP, 2014), um dos grandes limitantes do SSD, principalmente nas regiões de inverno seco, a cobertura dos solos na entressafra tem sido baixa, devio à falta de rotação e sucessão de culturas.

Nos últimos anos, alguns trabalhos que visavam a estudar plantas de cobertura para áreas de produção de grãos foram realizados em solos sob cerrado de vários estados (SABUNDJIAN et al., 2014; TORRES; PEREIRA; FABIAN, 2008). Porém, esses estudos se limitaram às espécies utilizadas para grãos, levando ao déficit de informações na literatura sobre espécies de cobertura em sucessão a espécies utilizadas para silagem.

Efeitos benéficos das espécies utilizadas na rotação de culturas no SSD já são conhecidos nas lavouras para produção de grãos. Algumas espécies, como a crotalária, possuem um sistema radicular profundo e capaciade de fixação biológica de nitrogênio $(\mathrm{N})$, possibilitando ciclagem mais eficiente de $\mathrm{N}$ no sistema de produção (DOURADO; BENETOLI; BOLONHEZI, 2001). O milheto, muito utilizado em consócio com a crotalária, possui como característica a elevada taxa de crescimento e tolerância à seca (CAZETTA; FORNASIERI FILHO; GIROTTO, 2005), o que contribui para seu desenvolvimento em regiões de inverno seco.

As braquiárias são utilizadas no SSD principalmente por proporcionar boa cobertura do solo, atuando na supressão de plantas daninhas (Pacheco et al., 2008), além de serem pouco exigentes em fertilidade. Por sua vez, o girassol é uma espécie que possui boa adaptação às condições de baixa pluviosidade e apresenta alta produção de massa seca (Sodré Filho et al., 2004). O nabo forrageiro já é utilizado há muito tempo como adubo verde, pois possui raízes que podem promover a descompactação do solo, influenciando também na melhoria dos atributos físicos do solo.

O manejo inadequado dos solos de muitas áreas de produção de silagem pode resultar na redução dos teores de matéria orgânica do solo (MO), além de provocar perdas de solo e de nutrientes por erosão, como observado por alguns autores em áreas de produção de grãos (CERDA et al., 2009; MELERO et al., 2009). Por outro lado, as principais vantagens voltadas para o uso de plantas de cobertura são o melhor aproveitamento dos nutrientes, devido à diminuição das perdas por erosão e o aumento do teor de MO, que implica em melhorias nas propriedades físicas, químicas e biológicas do solo (SOLDEVILLA-MARTINEZ et al., 2013). Nesse sentido, fica claro que a sucessão/rotação de culturas contribui 
para manutenção do equilíbrio dos nutrientes no solo e para o aumento da sua fertilidade, como também permite uma melhor utilização dos insumos agrícolas (CARVALHO et al., 2004).

Conduziu-se a hipótese de que as plantas de cobertura proporcionam maior acúmulo de massa seca e de nutrientes na parte aérea das plantas de milho, quando cultivadas em sucessão ao milho para silagem. Muitas espécies de cobertura apresentam sistema radicular capaz de absorver os nutrientes das camadas mais profundas dos solos, trazendo-os para as camadas superficiais, devido à decomposição dos seus restos culturais na superfície dos solos. Desta forma, o objetivo deste trabalho foi avaliar o efeito de diferentes plantas de cobertura no acúmulo de nutrientes e produtividade de MS na parte aérea das plantas de milho, em área de produção de silagem, na Região Central de Minas Gerais.

\section{MATERIAL E MÉTODOS}

O trabalho foi desenvolvido na Fazenda São João (19-25'48" de latitude Sul e 4429' 41" de longitude Oeste), situada no município de Inhaúma, MG. O experimento foi conduzido em duas safras, 2012/2013 e 2013/2014. Na figura 1, são apresentadas as precipitações durante o período de condução do experimento.

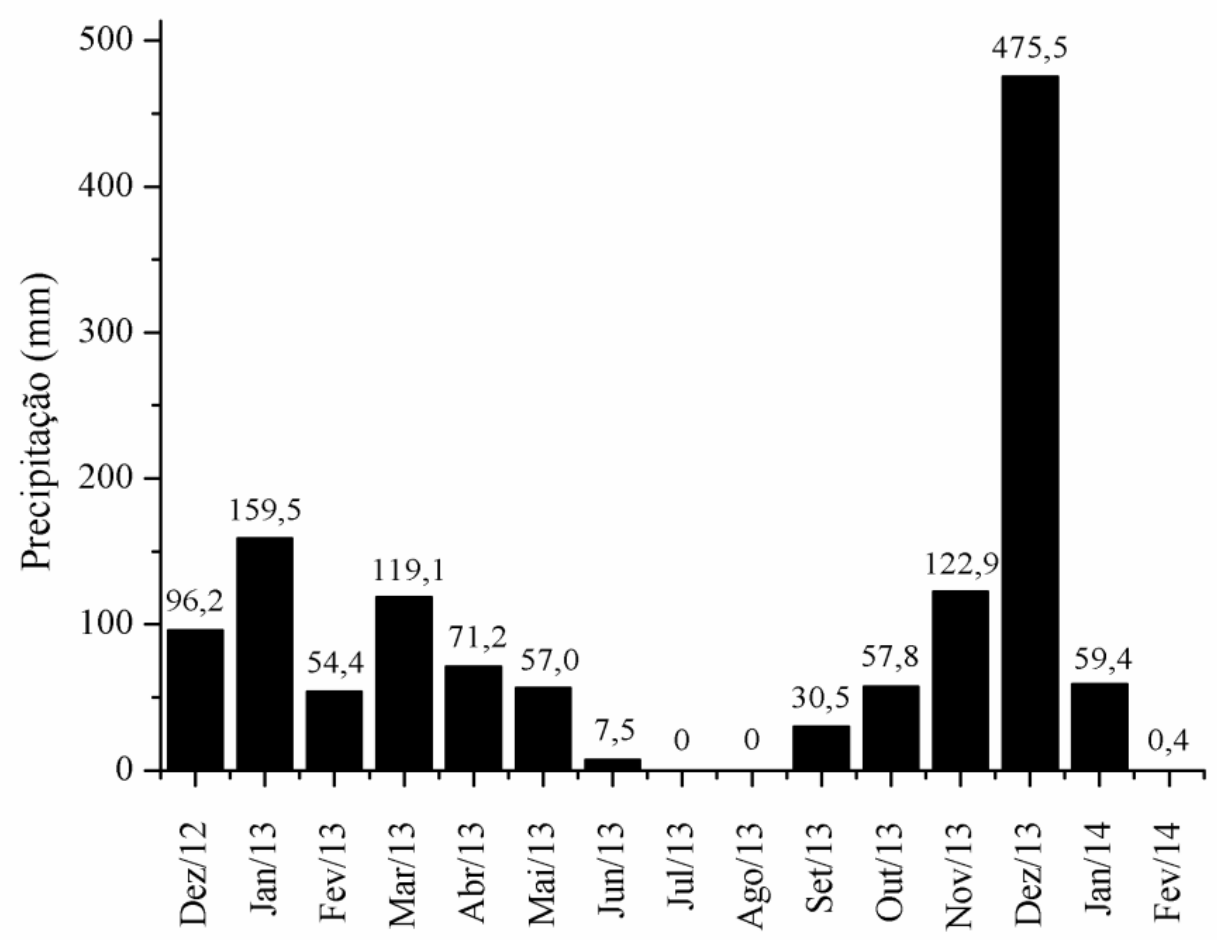

Figura 1. Precipitação acumulada por mês no período de 1ㅇ de dezembro de 2012 a 28 de fevereiro de 2014.

Figure 1. Cumulative rainfall per month in the period from $1^{\text {st }}$ December, 2012 to $28^{\text {th }}$ February, 2014.

Foram coletadas amostras de solo (Latossolo Vermelho Amarelo distrófico) na profundidade de $0-20 \mathrm{~cm}$, para caracterização química e física, antes da implantação do experimento (Tabela 1). As análises foram executadas utilizando-se os métodos e extratores de rotina, conforme metódos descritos em Silva (2009). 
O experimento foi instalado, utilizando-se delineamento experimental em blocos casualizados, com quatro repetições. Cada parcela teve dimensão de 6,6 × 20 m (132 $\mathrm{m}^{2}$ ). A dimensão de 6,6 $\mathrm{m}$ correspondeu a 11 linhas de milho espaçadas a 0,6 m entre linhas, espaçamento adotado na fazenda. Para avaliação da produtividade, considerouse como área útil três linhas centrais, com $5 \mathrm{~m}$ de comprimento.

Tabela 1. Atributos químicos do solo, teores de nutrientes, areia, silte e argila das camadas de 0 a $20 \mathrm{~cm}$, na Fazenda São João, em Inhaúma-MG, antes da implantação do experimento.

Table 1. Chemical attributes of soil, nutrient, sand, silt and clay contents of 0 to $20 \mathrm{~cm}$ layers, at Fazenda São João, in Inhaúma-MG, prior to the experiment.

\begin{tabular}{|c|c|c|c|}
\hline \multicolumn{2}{|l|}{ Análises } & \multicolumn{2}{|l|}{ Análises } \\
\hline M.O (\%) & 3,2 & CTC $\left(\mathrm{cmol}_{\mathrm{c}} \mathrm{dm}^{-3}\right)$ & 8,2 \\
\hline pH em água & 6,0 & Saturação por Base (\%) & 56 \\
\hline $\mathrm{Al}^{3+}\left(\mathrm{cmol}_{\mathrm{c}} \mathrm{dm}^{-3}\right)$ & 0 & $\mathrm{~B}\left(\mathrm{mg} \mathrm{dm}^{-3}\right)$ & 0,3 \\
\hline $\mathrm{H}+\mathrm{Al}\left(\mathrm{cmol}_{\mathrm{c}} \mathrm{dm}^{-3}\right)$ & 3,6 & $\mathrm{Cu}\left(\mathrm{mg} \mathrm{dm}^{-3}\right)$ & 1,2 \\
\hline P Mechlich ${ }^{-1}\left(\mathrm{mg} \mathrm{dm}^{-3}\right)$ & 30 & $\mathrm{Fe}\left(\mathrm{mg} \mathrm{dm}^{-3}\right)$ & 42 \\
\hline P Resina $\left(\mathrm{mg} \mathrm{dm}^{-3}\right)$ & 52 & $\mathrm{Mn}\left(\mathrm{mg} \mathrm{dm}^{3}\right)$ & 24,6 \\
\hline $\mathrm{K}^{+}\left(\mathrm{mg} \mathrm{dm}^{-3}\right)$ & 124 & $\mathrm{Zn}\left(\mathrm{mg} \mathrm{dm}^{-3}\right)$ & 1,9 \\
\hline $\mathrm{Ca}^{2+}\left(\mathrm{cmol}_{\mathrm{c}} \mathrm{dm}^{-3}\right)$ & 3,2 & Areia $\left(\mathrm{g} \mathrm{kg}^{-1}\right)$ & 472 \\
\hline $\mathrm{Mg}^{2+}\left(\mathrm{cmol}_{\mathrm{c}} \mathrm{dm}^{-3}\right)$ & 1,1 & Silte $\left(\mathrm{g} \mathrm{kg}^{-1}\right)$ & 75 \\
\hline S.B $\left(\mathrm{cmol}_{\mathrm{c}} \mathrm{dm}^{-3}\right)$ & 4,6 & $\operatorname{Argila}\left(\mathrm{g} \mathrm{kg}^{-1}\right)$ & 453 \\
\hline
\end{tabular}

Foram empregados oito tratamentos constituídos por seis espécies de cobertura: nabo forrageiro (Raphanus sativus (L.), milheto (Pennisetum americanum (L.) Leek cv. ADR 500), braquiária ruziziensis (Brachiaria ruzziziensis R. Germ \& Evrad), braquiária decumbens (Brachiaria decumbens Stapf), crotalária (Crotalaria spectabilis Roth) $e$ girassol (Helianthus annuus (L.)), além de um tratamento composto pela mistura das espécies milheto e crotalária e uma área de pousio, como controle, totalizando-se 32 parcelas (oito tratamentos com quatro repetições). Em março de 2012, antes da semeadura das plantas de cobertura, todas parcelas foram subsoladas a $25 \mathrm{~cm}$, com subsolador com rolo destorroador traseiro, com disco de corte na parte frontal e com presença de cinco hastes, espaçadas a $40 \mathrm{~cm}$.

A distribuição das sementes das plantas de cobertura foi realizada de forma manual, a lanço. Objetivando aumentar a qualidade na distribuição das sementes, misturou-se às sementes de cada parcela, uma quantidade fixa de areia (5 litros por parcela). As quantidades de sementes utilizadas em cada parcela foram: $20 \mathrm{~kg} \mathrm{ha}^{-1} \mathrm{de}$ sementes para ambas as braquiárias; $25 \mathrm{~kg} \mathrm{ha}^{-1}$ para crotalária e $15 \mathrm{~kg} \mathrm{ha}^{-1}$ para girassol, nabo e milheto. Imediatamente, após a distribuição das plantas de cobertura, foi realizada uma incorporação com grade leve fechada (profundidade aproximada de 5 $\mathrm{cm})$.

A semeadura das culturas de cobertura foi realizada no dia 15 de março de 2012. No ano de 2013, as plantas de cobertura foram semeadas no dia 12 de abril. A implantação ocorreu sempre após a colheita das plantas de milho para silagem.

No ano de 2012, após 90 dias da semeadura das plantas de cobertura, avaliou-se a produtividade de MS e realizou-se a roçada de todas as plantas de cobertura. No ano de 2013, a produtividade de MS das plantas de cobertura não foi avaliada, devido às falhas de germinação das plantas de cobertura, em decorrência da falta de chuvas na região (Figura 1). Portanto, na safra de milho desse ano, foi avaliado apenas o efeito residual das plantas de cobertura, que ainda sobraram na área do cultivo anterior.

As avaliações de produtividade de MS das plantas de cobertura foram feitas em três pontos, por parcela, utilizando-se um quadrado de 0,5 $\mathrm{m}$ de dimensão. As plantas foram cortadas rente ao solo e imediatamente pesadas no campo. Após a pesagem 
realizada no campo, as amostras foram levadas ao laboratório, as quais foram secas em estufa a $60^{\circ} \mathrm{C}$, moídas e submetidas à análise química para determinação dos teores totais de nutrientes (C, N, P, K, Mg, Ca, S, Cu, Fe, Mn e Zn), segundo Malavolta; Vitti e Oliveira (1997). As quantidades acumuladas de nutrientes nas plantas de cobertura foram calculadas, baseando-se na concentração de nutrientes na parte aérea das plantas de cobertura $\left(\mathrm{g} \mathrm{kg}^{-1}\right)$ e na $\mathrm{MS}(\mathrm{kg})$ produzida na área amostrada $(0,5 \times 0,5 \mathrm{~m})$. Posteriormente, as quantidades acumuladas foram extrapoladas para um hectare $\left(10000 \mathrm{~m}^{2}\right)$.

Nas plantas de cobertura, foram determinadas as porcentagens de cobertura do solo. Para isso, utilizou-se um quadrado de madeira de $0,5 \mathrm{~m}$ de lado, com rede de barbantes a cada $0,05 \mathrm{~m}$, em que foi observada a presença de cobertura proporcionada pelas diferentes culturas de cobertura e plantas daninhas, de acordo com a metodologia utilizada por Sodré-Filho et al. (2004). As avaliações foram feitas após a morte das plantas pelo manejo químico e, posterior roçada da área. Toda a gleba foi dessecada utilizando-se glifosato (1440 $\mathrm{g} \mathrm{ha}^{-1}$ de ingrediente ativo).

Na semeadura do milho, realizada no dia 21 de novembro de 2012, utilizou-se em toda a gleba, o híbrido Riber $9308 \mathrm{H}$, com espaçamento de $0,6 \mathrm{~m}$ entre linhas, com 3,6 sementes por metro linear ( 60000 sementes $\left.\mathrm{ha}^{-1}\right)$. As sementes utilizadas também foram tratadas com inseticidas, princípios ativos (PA) imidacropido e tiodicarbe, nas dosagens de 45 e 135 gramas de PA ha-1 $^{-1}$, respectivamente.

Antes da semeadura do milho, foi aplicada em toda a gleba $1 \mathrm{t} \mathrm{ha}{ }^{-1}$ de gesso agrícola, visando ao fornecimento de enxofre. Na adubação de base, foram aplicados, respectivamente, 32,80 e $64 \mathrm{~kg}^{-1} \mathrm{de} \mathrm{N}^{-} \mathrm{P}_{2} \mathrm{O}_{5}$ e $\mathrm{K}_{2} \mathrm{O}$ no sulco de semeadura. Nesse mesmo dia, também foram aplicados a lanço $120 \mathrm{~kg} \mathrm{ha}^{-1}$ de $\mathrm{K}_{2} \mathrm{O}$. A adubação de cobertura, realizada a lanço, ocorreu no estágio V4 da cultura, com $135 \mathrm{~kg} \mathrm{ha}^{-1} \mathrm{de} \mathrm{N}$, utilizando-se uréia como fonte. Antes da adubação de cobertura, foi realizado manejo químico de ervas daninhas com herbicidas atrazina (125 g ha-1 de PA) e tebotriona (76 g ha-1 de PA).

No ano de 2013, na mesma área descrita anteriormente, procedeu-se a roçada de todas as parcelas, no mês de setembro de 2013, para uniformizar a área para brotação e, posterior, dessecagem com glifosato ( $1680 \mathrm{~g} \mathrm{ha}^{-1}$ de ingrediente ativo). Na semeadura do milho, realizada no dia 25 de outubro de 2013, utilizou-se em toda a gleba, o híbrido $30 \mathrm{~F} 35 \mathrm{H}$, no espaçamento de $0,6 \mathrm{~m}$ entre linhas, com 3,6 sementes por metro linear ( 60000 sementes $\left.\mathrm{ha}^{-1}\right)$. As sementes utilizadas também foram tratadas com inseticidas, conforme já descrito neste trabalho.

$\mathrm{Na}$ adubação de base, foram aplicados $39 \mathrm{~kg} \mathrm{ha}^{-1}$ de $\mathrm{N}$ e $99 \mathrm{~kg} \mathrm{ha}^{-1}$ de $\mathrm{P}_{2} \mathrm{O}_{5}$ no sulco de semeadura e $180 \mathrm{~kg} \mathrm{ha}^{-1}$ de $\mathrm{K}_{2} \mathrm{O}$ a lanço. A adubação de cobertura, realizada a lanço, ocorreu no estágio V4 da cultura, com $135 \mathrm{~kg} \mathrm{ha}^{-1}$ de $\mathrm{N}$, e uréia com fonte. Antes da adubação de cobertura, foi realizado manejo químico de ervas daninhas com herbicidas atrazina (125 $\mathrm{g} \mathrm{ha}^{-1}$ de PA) e tebotriona (76 $\left.\mathrm{g} \mathrm{ha}^{-1} \mathrm{de} \mathrm{PA}\right)$.

Para a determinação da produtividade de MS das plantas de milho, foram colhidas as plantas de três fileiras centrais de cada parcela, com três metros de comprimento, as quais foram pesadas, imediatamente, após a colheita. Após pesagem dos materiais a campo, foram escolhidas cinco plantas por parcela, para pesagem no campo e posterior determinação de MS e dos teores de nutrientes.

Após a pesagem dos materiais em campo, a parte aérea das plantas foi seca em estufa a 60 으, até peso constante e, em seguida, moída. Posteriormente, foram determinados os teores de nutrientes ( $N, P, K, C a, M g, S, C u, F e, M n$ e $\mathrm{Zn}$ ) na parte aérea das plantas, conforme Malavolta, Vitti e Oliveira (1997). As quantidades acumuladas de macronutrientes e micronutrientes nas plantas de milho foram calculadas, baseando-se na concentração de nutrientes na parte aérea, essas quantidades foram obtidas nas 
cinco plantas selecionadas, considerando-se a quantidade de MS produzida na parcela. Posteriormente, as quantidades acumuladas foram extrapoladas para um hectare $\left(10000 \mathrm{~m}^{2}\right)$. O mesmo procedimento foi adotado durante a colheita do milho da safra seguinte (2013).

Todos os dados obtidos foram submetidos a análises de variância e testes de média. As médias foram comparadas pelo teste de Tukey $(P<0,05)$.

\section{RESULTADOS E DISCUSSÃO}

As culturas do girassol e do milheto destacaram-se na produção de MS (Tabela 2), assim como fora observado no trabalho de Moreira et al. (2014), também na região Central de Minas Gerais. Para Alvarenga et al. (2001), a quantidade mínima de palha necessária para manutenção do SSD é de $6 \mathrm{t} \mathrm{ha}^{-1}$. Neste trabalho, apenas os tratamentos compostos por girassol e milheto apresentaram MS superior ao recomendado por esses autores. Embora o nabo forrageiro tenha apresentado desenvolvimento inferior aos valores recomendados por Alvarenga et al. (2001), a produção de MS foi muito superior ao citado por Derpsch e Calegari (1992), nas condições do estado do Paraná, em que foi obtida produtividade média de $3 \mathrm{t} \mathrm{ha-1}$.

Tabela 2. Produtividade de massa seca (MS) da parte aérea das plantas de cobertura e porcentagem de cobertura do solo após o corte (PCAC) e após a semeadura (PCAS) do milho, no ano de 2012.

Table 2. Dry matter yield (DM) of the aerial part of the cover plants and percentage of soil cover after cutting (PCAC) and after sowing (PCAS) of corn, in the year of 2012.

\begin{tabular}{lccc}
\hline Tratamentos & $\mathrm{MS}\left(\mathrm{t} \mathrm{ha}^{-1}\right)$ & PCAC (\%) & PCAS (\%) \\
\hline Girassol & $15,6 \mathrm{~A}$ & 78,7 & 42,5 \\
Milheto & $8,2 \mathrm{~B}$ & 81,9 & 47,5 \\
Crotalária + Milheto & $5,9 \mathrm{BC}$ & 46,7 & 25 \\
Nabo Forrageiro & $5,6 \mathrm{BC}$ & 56,4 & 21,3 \\
B. Ruziziensis & $4,3 \mathrm{BC}$ & 59,1 & 25 \\
B. Decumbens & $4,2 \mathrm{C}$ & 74,6 & 45 \\
Pousio & $4,1 \mathrm{C}$ & 76,5 & 40 \\
Crotalária spectabilis & $2,3 \mathrm{C}$ & 50,2 & 22,5 \\
\hline
\end{tabular}

Médias seguidas de mesmas letras na coluna, não diferem entre si pelo teste de Tukey, a 5 \% de significância. Averages followed by the same letters in the column, do not differ by Tukey test, at $5 \%$ of significance.

Embora não tenha sido quantificado no experimento, foi possível observar, durante a condução experimento, que as culturas de cobertura que apresentaram menor infestação de plantas daninhas durante o ciclo, foram o girassol, nabo forrageiro, milheto e o tratamento composto pela mistura de milheto e crotalária. No caso das culturas do girassol e milheto, provavelmente, a supressão das plantas daninhas tenha sido devido a sua maior produtividade de MS (Tabela 2). Segundo Balbinot Jr, Moraes e Backes (2007), a cobertura do solo proporcionada pela presença da palha pode proporcionar a supressão de plantas daninhas. Quando a palha se decompõe, pode liberar substâncias, como os aleloquímicos, que podem inibir a emergência ou o crescimento de plantas daninhas, em decorrência do efeito alelopático (SOUZA et al., 2006).

Plantas de cobertura como o nabo forrageiro, mesmo com menor produção de MS (Tabela 2), podem reduzir a infestação de plantas daninhas, como observado no presente estudo. Isso ocorre porque o nabo forrageiro apresenta efeito alelopático sobre as plantas daninhas (PAULETTI, 1999), conforme observado por Rizzardi e Silva (2006) durante o cultivo de milho, em sucessão ao nabo forrageiro. 
As quantidades de macronutrientes acumulados na parte aérea das diferentes plantas de cobertura foram baixas (Tabela 3 ), se comparadas às observadas por Moreira et al. (2014). As quantidades de MS produzidas por boa parte das plantas de cobertura no trabalho desses autores foram maiores que as observadas neste estudo, o que pode explicar as maiores quantidades acumuladas de $\mathrm{C}$ e $\mathrm{N}$. Provavelmente, as maiores produtividades de MS e quantidades acumuladas de nutrientes pelas plantas cultivadas por Moreira et al. (2014) se devem às melhores condições da fertilidade do solo da área utilizada, comparadas com o local utilizado no presente estudo.

Tabela 3. Acúmulo de macronutrientes na parte aérea, em tratamentos com diferentes plantas de cobertura, cultivadas em 2012.

Table 3. Macronutrient accumulation in shoot, in treatments with different cover crops, cultivated in 2012.

\begin{tabular}{|c|c|c|c|c|c|c|c|}
\hline Tratamentos & C & $\mathrm{N}$ & $P$ & $\begin{array}{c}\mathrm{K} \\
\mathrm{kg} \mathrm{ha} \\
\end{array}$ & $\mathrm{Ca}$ & $\mathrm{Mg}$ & $S$ \\
\hline B. Decumbens & $1489 A B$ & $82 \mathrm{~B}$ & $6 \mathrm{C}$ & $87,0 \mathrm{ABC}$ & $25,2 \mathrm{D}$ & $13,9 \mathrm{BC}$ & $10,0 \mathrm{AB}$ \\
\hline B. Ruziziensis & 1466B & $88 \mathrm{AB}$ & $5,5 \mathrm{CD}$ & $94,0 A B$ & $24,1 \mathrm{D}$ & $12,2 \mathrm{BCD}$ & $9,6 \mathrm{AB}$ \\
\hline Crotalária spectabilis & 1438 B & $96 \mathrm{~A}$ & $8,5 \mathrm{~B}$ & $92,1 A B$ & $49,1 A B$ & $16,9 \mathrm{~B}$ & $15,1 \mathrm{AB}$ \\
\hline Girassol & $1555 \mathrm{~A}$ & $60 \mathrm{C}$ & $5,4 \mathrm{CD}$ & $71,2 \mathrm{BC}$ & $38,6 \mathrm{C}$ & $8,2 \mathrm{D}$ & $11,1 \mathrm{AB}$ \\
\hline Nabo Forrageiro & 1464 B & $90 A B$ & $10,5 \mathrm{~A}$ & $84,2 \mathrm{ABC}$ & $42,7 \mathrm{BC}$ & $10 \mathrm{CD}$ & $21,3 \mathrm{~A}$ \\
\hline Milheto & 1466 B & $53 C$ & $4,1 \mathrm{D}$ & $64,4 \mathrm{C}$ & $13,9 \mathrm{E}$ & $7,5 \mathrm{D}$ & $4,3 \mathrm{~B}$ \\
\hline Crotalária + Milheto & $1501 \mathrm{AB}$ & $62 \mathrm{C}$ & $4,5 \mathrm{CD}$ & $67,3 \mathrm{C}$ & $17,4 \mathrm{DE}$ & $8,5 \mathrm{D}$ & $4,5 \mathrm{~B}$ \\
\hline Pousio & 1427 B & $83 \mathrm{~B}$ & $9,1 A B$ & $99,8 \mathrm{~A}$ & $53,7 \mathrm{~A}$ & $22,6 \mathrm{~A}$ & $8,6 \mathrm{~B}$ \\
\hline
\end{tabular}

Médias seguidas de mesmas letras na coluna, não diferem entre si pelo teste de Tukey, a 5 \% de significância.

Averages followed by the same letters in the column, do not differ by Tukey test, at 5\% of significance.

As quantidades de $\mathrm{C}$ acumuladas variaram pouco com as plantas de cobertura, sendo que, os maiores acúmulos ocorreram nas plantas de girassol, provavelmente devido à sua maior produção de MS. No caso do N, os maiores acúmulos ocorreram nas plantas de crotalária, braquiária ruziziensis e o nabo forrageiro (Tabela 3). Perin et al. (2004) avaliando o efeito do cultivo de crotalária e do milheto no acúmulo de nutrientes, também encontraram na leguminosa, acúmulos mais elevados de N. Para a crotalária, esse maior acúmulo de $\mathrm{N}$, comparado as outras plantas de cobertura, pode ser parcialmente explicado, devido a sua capacidade de fixação biológica do N (FBN) (PERIN et al., 2004).

Os maiores acúmulos de $\mathrm{P}$ foram observados nas plantas de nabo forrageiro, mas foram semelhantes aos observados na área de pousio, na qual houve grande desenvolvimento de plantas daninhas. As plantas daninhas da área de pousio também acumularam grandes quantidades de $\mathrm{K}, \mathrm{Ca}$ e $\mathrm{Mg}$ (Tabela 3). A presença de plantas daninhas nessas áreas constitui riscos para a produção de silagem, isso porque a maior quantidade de nutrientes acumulados contribui para o fortalecimento e dispersão dessas plantas na área. Desta forma, a rotação de culturas utilizando espécies com diferentes ciclos de vida, pode reduzir o sucesso do estabelecimento das plantas daninhas (MONQUERO; CHRISTOFFOLETI, 2005), já que a ausência de rotação favorece o surgimento de espécies resistentes (VIDAL; LAMEGO; TREZZI, 2006).

As plantas de nabo forrageiro, crotalária, girassol e as braquiárias obtiveram maiores acúmulos de $S$, sendo que, o nabo forrageiro foi a espécie que se destacou no acúmulo de $\mathrm{S}$ (Tabela 3). Esse fato justifica-se pela grande exigência do nabo forrageiro em $\mathrm{S}$, o qual apresenta alta capacidade de absorção e acúmulo desse nutriente (RHEINHEIMERET al., 2005).

No caso dos micronutrientes acumulados pela parte aérea das diferentes espécies de cobertura estudadas, houve uma grande variação entre as plantas de cobertura (Tabela 4). Se, por um lado, o nabo forrageiro apresentou uma das maiores quantidades 
acumuladas de $\mathrm{Zn}$, por outro lado também foi uma das espécies que acumulou as menores quantidades de $\mathrm{Cu}$ e $\mathrm{Mn}$. De modo geral, a crotalária foi a planta que apresentou as maiores quantidades de todos os micronutrientes avaliados, enquanto que o girassol se destacou pelo mais elevado acúmulo de $\mathrm{Cu}$.

Nos estudos de Braz et al. (2004), o milheto acumulou a menor quantidade de $\mathrm{Fe}$ (3797 $\mathrm{g} \mathrm{ha}^{-1}$ ), comparado com o capim braquiária e o mombaça, após 80 dias de emegência. De qualquer forma, as plantas de milheto, cultivadas por Braz et al. (2004), apresentaram um acúmulo de Fe muito superior ao observado no presente estudo.

Tabela 4. Acúmulo de micronutrientes na parte aérea de plantas de cobertura, cultivadas em 2012.

Table 4. Micronutrient accumulation in the aerial part of cover crops, cultivated in 2012.

\begin{tabular}{|c|c|c|c|c|}
\hline \multirow{2}{*}{ Tratamentos } & $\mathrm{Cu}$ & $\mathrm{Fe}$ & $\mathrm{Mn}$ & $\mathrm{Zn}$ \\
\hline & \multicolumn{4}{|c|}{$\mathrm{g} \mathrm{ha}^{-1} \longrightarrow$} \\
\hline B. Decumbens & $15,5 \mathrm{BCD}$ & 1019,9 ABC & $320,8 \mathrm{~A}$ & $69,5 \mathrm{C}$ \\
\hline B. Ruziziensis & $13,8 \mathrm{CD}$ & $850,9 \mathrm{C}$ & $268,2 A B$ & $75,1 \mathrm{BC}$ \\
\hline Crotalária spectabilis & $21,5 \mathrm{AB}$ & $1430,5 \mathrm{~A}$ & $301,4 \mathrm{~A}$ & $104,7 \mathrm{~A}$ \\
\hline Girassol & $23,5 \mathrm{~A}$ & $728,3 \mathrm{C}$ & $154,9 \mathrm{BC}$ & $68,7 \mathrm{C}$ \\
\hline Nabo Forrageiro & $8,7 \mathrm{D}$ & $762,9 \mathrm{C}$ & $143,8 \mathrm{C}$ & $108,3 \mathrm{~A}$ \\
\hline Milheto ADR 500 & $14,7 \mathrm{BCD}$ & $878 \mathrm{BC}$ & $274,5 \mathrm{AB}$ & $58,9 \mathrm{C}$ \\
\hline Crotalária + Milheto & $16,1 \mathrm{BC}$ & $816,1 \mathrm{C}$ & $262,7 \mathrm{ABC}$ & $67,5 \mathrm{C}$ \\
\hline Pousio & $16,4 \mathrm{BC}$ & $1405,7 \mathrm{AB}$ & $341,4 \mathrm{~A}$ & $96,5 \mathrm{AB}$ \\
\hline
\end{tabular}

Médias seguidas de mesmas letras na coluna, não diferem entre si pelo teste de Tukey, a 5 \% de significância.

Averages followed by the same letters in the column, do not differ by Tukey test, at $5 \%$ of significance.

Nos dois anos de cultivo, as produtividades totais de MS do milho cultivado, após as plantas de cobertura, não variaram. Apenas no segundo ano houve um pequeno aumento na massa de folhas do milho cultivado na área com girassol (Tabela 5). As produtividades totais de MS do milho foram semelhantes às encontradas em trabalhos conduzidos em SSD, os quais mostram produtividade variando entre 15 e $20 \mathrm{t} \mathrm{ha}^{-1}$ de MS, dependendo da cultivar utilizada (COELHO; FRANÇA 1995; Duarte et al., 2003; GUARESCHI et al., 2008), e encontram-se dentro do esperado para a produção de silagem.

Em estudo desenvolvido na região central de Minas Gerais por Moreira et al. (2014), em condições climáticas similares, as produtividades de MS das diferentes frações da planta de milho (folha, colmo e espiga), assim como a produtividade de MS da parte aérea total das plantas de milho, também não variaram com as plantas de cobertura.

Acredita-se que não houve resposta na produtividade do milho, em função das culturas antecessoras, devido às condições climáticas desfavoráveis ao seu cultivo, pois houve um veranico entre os meses de dezembro de 2012 a fevereiro de 2013 (Figura 1), o qual iniciou no estágio V4 da cultura, imediatamente após a adubação de cobertura. Na safra 2013/2014, também houve um veranico em janeiro de 2014, com baixa distribuição de chuvas em novembro de 2013 (Figura 1).

Em todas as parcelas, foram utilizados, durante o cultivo do milho, $167 \mathrm{~kg} \mathrm{ha}^{-1} \mathrm{de}$ $\mathrm{N}$, no primeiro ano de condução, e $174 \mathrm{~kg} \mathrm{ha}^{-1}$, no segundo ano. Ribeiro; Guimarães e Alvarez V. (1999) recomendam dose de $\mathrm{N}$ semelhante à utilizada para se produzir de 40 a $50 \mathrm{t} \mathrm{ha}^{-1}$ de silagem (massa natural). No presente estudo, a produtividade de massa natural variou de $42\left(13,92 \mathrm{t} \mathrm{ha}^{-1} \mathrm{com} 33 \%\right.$ de MS) a 48 (15,85 t ha- ${ }^{-1}$ com $33 \%$ de MS). Assim, dentro de condições climáticas limitantes à alta produtividade, possivelmente, a adubação nitrogenada utilizada pode ter contribuído para normatizar as produtividades dentro de um mesmo patamar. 
Tabela 5. Produtividades de massa seca $\left(\mathrm{t} \mathrm{ha} \mathrm{H}^{-1}\right.$ ) das diferentes partes da planta de milho (folha, colmo e espiga) e produtividade total, em função das plantas de cobertura, nos anos de 2013 e 2014.

Table 5. Productivity of dry mass ( $t \mathrm{ha}^{-1}$ ) of the different parts of the corn plant (leaf, stem and spike) and total productivity, as a function of cover crops, in the years 2013 and 2014.

\begin{tabular}{|c|c|c|c|c|c|c|c|c|}
\hline \multirow{3}{*}{ Tratamentos } & \multirow{2}{*}{\multicolumn{2}{|c|}{$\begin{array}{l}\text { Folha } \\
\text { Safra }\end{array}$}} & \multirow{2}{*}{\multicolumn{2}{|c|}{$\begin{array}{c}\text { Colmo } \\
\text { Safra }\end{array}$}} & \multirow{2}{*}{\multicolumn{2}{|c|}{$\begin{array}{l}\text { Espiga } \\
\text { Safra }\end{array}$}} & \multirow{2}{*}{\multicolumn{2}{|c|}{$\begin{array}{l}\text { Total } \\
\text { Safra }\end{array}$}} \\
\hline & & & & & & & & \\
\hline & 2013 & 2014 & 2013 & 2014 & 2013 & 2014 & 2013 & 2014 \\
\hline B. Decumbens & $9,1 \mathrm{~A}$ & $4,2 \mathrm{AB}$ & $3,2 \mathrm{~A}$ & $3,4 \mathrm{~A}$ & $2,3 \mathrm{~A}$ & $7,4 \mathrm{~A}$ & $14,7 \mathrm{~A}$ & $15,1 \mathrm{~A}$ \\
\hline B. Ruziziensis & $8,6 \mathrm{~A}$ & $4,8 \mathrm{AB}$ & $2,8 \mathrm{~A}$ & $4,1 \mathrm{~A}$ & $2,3 \mathrm{~A}$ & $8,3 \mathrm{~A}$ & $13,6 \mathrm{~A}$ & $17,3 \mathrm{~A}$ \\
\hline Crotalária spectabilis & $9,2 \mathrm{~A}$ & $4,6 \mathrm{AB}$ & $2,8 \mathrm{~A}$ & $4,6 \mathrm{~A}$ & $3,3 \mathrm{~A}$ & $7,9 \mathrm{~A}$ & $14,4 \mathrm{~A}$ & $17,2 \mathrm{~A}$ \\
\hline Girassol & $9,7 \mathrm{~A}$ & $5,2 \mathrm{~A}$ & $3,1 \mathrm{~A}$ & $4,6 \mathrm{~A}$ & $2,2 \mathrm{~A}$ & $9,5 \mathrm{~A}$ & $14,9 \mathrm{~A}$ & $19,4 \mathrm{~A}$ \\
\hline Nabo Forrageiro & $9,3 \mathrm{~A}$ & $4,9 \mathrm{AB}$ & $2,8 \mathrm{~A}$ & $4,8 \mathrm{~A}$ & $2,2 \mathrm{~A}$ & $9,9 \mathrm{~A}$ & $14,3 \mathrm{~A}$ & $19,7 \mathrm{~A}$ \\
\hline Milheto & $10,1 \mathrm{~A}$ & $4,1 \mathrm{AB}$ & $3,2 \mathrm{~A}$ & $3,6 \mathrm{~A}$ & $2,5 \mathrm{~A}$ & $7,9 \mathrm{~A}$ & $15,8 \mathrm{~A}$ & $15,6 \mathrm{~A}$ \\
\hline Crotalária + Milheto & $8,6 \mathrm{~A}$ & $3,9 \mathrm{AB}$ & $3,1 \mathrm{~A}$ & $4,1 \mathrm{~A}$ & $2,1 \mathrm{~A}$ & $7,1 \mathrm{~A}$ & $13,8 \mathrm{~A}$ & $15, A$ \\
\hline Pousio & $8,8 \mathrm{~A}$ & $3,7 \mathrm{~B}$ & $2,6 \mathrm{~A}$ & $3,3 \mathrm{~A}$ & $2,4 \mathrm{~A}$ & $6,0 \mathrm{~A}$ & $13,9 \mathrm{~A}$ & $13,2 \mathrm{~A}$ \\
\hline
\end{tabular}

Para cada variável, em cada ano avaliado, médias seguidas de mesmas letras na coluna, não diferem entre si pelo teste de Tukey, a 5 \% de significância.

For each variable, in each evaluated year, averages followed by the same letters in the column, do not differ by Tukey test, at $5 \%$ of significance.

Com exceção das quantidades de Fe e $\mathrm{K}$ acumulados nas plantas de milho, as quantidades totais dos nutrientes acumulados na parte aérea não variaram com as plantas de cobertura (Tabelas 6 e 7). Ressalta-se que a pouca variação das quantidades de nutrientes acumulados nas plantas de milho pode estar relacionada com a produção da MS desses vegetais, a qual não variou com os tratamentos nesse ano de cultivo (Tabela 5).

Tabela 6. Macronutrientes totais acumulados $\left(\mathrm{kg} \mathrm{ha}^{-1}\right)$ nas plantas de milho, em função das diferentes plantas de cobertura, nos anos de 2013 e 2014.

Table 6. Total accumulated macronutrients $\left(\mathrm{kg} \mathrm{ha}^{-1}\right)$ in maize plants, according to the different coverage plants, in the years of 2013 and 2014.

\begin{tabular}{|c|c|c|c|c|c|c|}
\hline Tratamentos & $\mathrm{N}$ & $\mathrm{P}$ & $\mathrm{K}$ & $\mathrm{Ca}$ & $\mathrm{Mg}$ & $S$ \\
\hline \multicolumn{7}{|c|}{2013} \\
\hline B. Decumbens & $153,0 \mathrm{~A}$ & $27,1 \mathrm{~A}$ & $177,5 \mathrm{~A}$ & $17,2 \mathrm{~A}$ & $18,0 \mathrm{~A}$ & $12,4 \mathrm{~A}$ \\
\hline B. Ruziziensis & $139,5 A$ & $26,5 \mathrm{~A}$ & $158,3 \mathrm{~A}$ & $16,8 \mathrm{~A}$ & $16,8 \mathrm{~A}$ & $13,1 \mathrm{~A}$ \\
\hline Crotalária spectabilis & $149,2 \mathrm{~A}$ & $27,7 \mathrm{~A}$ & $179,5 \mathrm{~A}$ & $17,3 \mathrm{~A}$ & $18,2 \mathrm{~A}$ & $13,4 \mathrm{~A}$ \\
\hline Girassol & $159,2 \mathrm{~A}$ & $28,9 \mathrm{~A}$ & $171,0 \mathrm{~A}$ & $17,9 \mathrm{~A}$ & $19,4 \mathrm{~A}$ & $14,5 \mathrm{~A}$ \\
\hline Nabo Forrageiro & $148,7 \mathrm{~A}$ & $29,3 \mathrm{~A}$ & $180,1 \mathrm{~A}$ & $17,1 \mathrm{~A}$ & $18,0 \mathrm{~A}$ & $13,6 \mathrm{~A}$ \\
\hline Milheto & $167,8 \mathrm{~A}$ & $28,4 \mathrm{~A}$ & $191,7 \mathrm{~A}$ & $19,8 \mathrm{~A}$ & $18,5 \mathrm{~A}$ & $15,5 \mathrm{~A}$ \\
\hline Crotalária + Milheto & $147,2 \mathrm{~A}$ & $27,9 \mathrm{~A}$ & $164,6 \mathrm{~A}$ & $13,7 \mathrm{~A}$ & $15,8 \mathrm{~A}$ & $12,3 \mathrm{~A}$ \\
\hline Pousio & $162,2 \mathrm{~A}$ & $28,4 \mathrm{~A}$ & $197,1 \mathrm{~A}$ & $20,2 \mathrm{~A}$ & $18,8 \mathrm{~A}$ & $14,1 \mathrm{~A}$ \\
\hline \multicolumn{7}{|c|}{2014} \\
\hline B. Decumbens & $98,8 \mathrm{~A}$ & $11,2 \mathrm{~A}$ & $149,2 \mathrm{C}$ & $18,7 \mathrm{~A}$ & $16,6 \mathrm{~A}$ & $9,5 \mathrm{~A}$ \\
\hline B. Ruziziensis & $103,4 \mathrm{~A}$ & $12,1 \mathrm{~A}$ & $218,1 \mathrm{CB}$ & $17,2 \mathrm{~A}$ & $19,7 \mathrm{~A}$ & $10,8 \mathrm{~A}$ \\
\hline Crotalária & $135,8 \mathrm{~A}$ & $21,0 \mathrm{~A}$ & $244,8 \mathrm{CB}$ & $24,7 \mathrm{~A}$ & $25,5 \mathrm{~A}$ & $13,6 \mathrm{~A}$ \\
\hline Girassol & $149,2 \mathrm{~A}$ & $19,8 \mathrm{~A}$ & $278,8 \mathrm{ABC}$ & $30,9 \mathrm{~A}$ & $27,0 \mathrm{~A}$ & $18,1 \mathrm{~A}$ \\
\hline Nabo Forrageiro & $103,4 \mathrm{~A}$ & $12,1 \mathrm{~A}$ & $218,1 \mathrm{AC}$ & $17,2 \mathrm{~A}$ & $19,7 \mathrm{~A}$ & $10,8 \mathrm{~A}$ \\
\hline Milheto ADR 500 & $233,0 \mathrm{~A}$ & $21,2 \mathrm{~A}$ & $377,6 \mathrm{AC}$ & $30,5 \mathrm{~A}$ & $34,7 \mathrm{~A}$ & $18,8 \mathrm{~A}$ \\
\hline Crotalária + Milheto & $192,5 \mathrm{~A}$ & $29,8 \mathrm{~A}$ & $375,9 \mathrm{AB}$ & $23,5 \mathrm{~A}$ & $38,1 \mathrm{~A}$ & $20,2 \mathrm{~A}$ \\
\hline Pousio & $246,5 \mathrm{~A}$ & $39,9 \mathrm{~A}$ & $442,1 \mathrm{~A}$ & $22,9 \mathrm{~A}$ & $45,6 \mathrm{~A}$ & $21,8 \mathrm{~A}$ \\
\hline
\end{tabular}

Para cada ano avaliado, médias seguidas de mesmas letras na coluna, não diferem entre si pelo teste de Tukey, a $5 \%$ de significância.

For each evaluated year, averages followed by the same letters in the column, do not differ by Tukey test, at 5\% of significance. 
Tabela 7. Micronutrientes totais acumulados $\left(\mathrm{g} \mathrm{ha}^{-1}\right)$ nas plantas de milho, em função das diferentes plantas de cobertura, em 2013 e 2014.

Table 7. Cumulative total micronutrients $\left(\mathrm{g} \mathrm{h} \mathrm{a}^{-1}\right)$ in maize plants, according to different coverage plants, in 2013 and 2014.

\begin{tabular}{lccccc}
\hline \multicolumn{1}{c}{ Tratamentos } & $\mathrm{B}$ & $\mathrm{Cu}$ & $\mathrm{Fe}$ & $\mathrm{Mn}$ & $\mathrm{Zn}$ \\
\cline { 2 - 6 } & & & 2013 & & $353,5 \mathrm{~A}$ \\
B. Decumbens & $66,0 \mathrm{~A}$ & $119,0 \mathrm{~A}$ & $4893,9 \mathrm{~A}$ & $501,0 \mathrm{~A}$ & $369,8 \mathrm{~A}$ \\
B. Ruziziensis & $61,3 \mathrm{~A}$ & $109,1 \mathrm{~A}$ & $2514,9 \mathrm{AB}$ & $530,1 \mathrm{~A}$ & $372,9 \mathrm{~A}$ \\
Crotalária spectabilis & $66,7 \mathrm{~A}$ & $98,9 \mathrm{~A}$ & $2029,0 \mathrm{AB}$ & $590,0 \mathrm{~A}$ & $389,5 \mathrm{~A}$ \\
Girassol & $61,1 \mathrm{~A}$ & $126,1 \mathrm{~A}$ & $3039,1 \mathrm{AB}$ & $581,5 \mathrm{~A}$ & $399,2 \mathrm{~A}$ \\
Nabo Forrageiro & $62,9 \mathrm{~A}$ & $105,9 \mathrm{~A}$ & $2581,6 \mathrm{AB}$ & $564,3 \mathrm{~A}$ & $408,0 \mathrm{~A}$ \\
Milheto & $73,6 \mathrm{~A}$ & $106,4 \mathrm{~A}$ & $2560,1 \mathrm{AB}$ & $680,5 \mathrm{~A}$ & $376,4 \mathrm{~A}$ \\
Crotalária + Milheto & $61,1 \mathrm{~A}$ & $92,2 \mathrm{~A}$ & $1743,8 \mathrm{~B}$ & $519,3 \mathrm{~A}$ & $372,6 \mathrm{~A}$ \\
Pousio & $66,1 \mathrm{~A}$ & $118,7 \mathrm{~A}$ & $3007,5 \mathrm{AB}$ & $593,6 \mathrm{~A}$ & \\
\hline & & & & & $171,3 \mathrm{~A}$ \\
B. Decumbens & $71,0 \mathrm{D}$ & $65,2 \mathrm{D}$ & $2640,2 \mathrm{~B}$ & $366,4 \mathrm{~A}$ & $236,1 \mathrm{~A}$ \\
B. Ruziziensis & $99,6 \mathrm{CD}$ & $92,1 \mathrm{CD}$ & $3046,6 \mathrm{AB}$ & $543,8 \mathrm{~A}$ & $273,0 \mathrm{~A}$ \\
Crotalária & $122,4 \mathrm{BCD}$ & $148,8 \mathrm{BCD}$ & $3568,2 \mathrm{AB}$ & $572,5 \mathrm{~A}$ & $266,4 \mathrm{~A}$ \\
Girassol & $140,3 \mathrm{BCD}$ & $128,7 \mathrm{BCD}$ & $3720,4 \mathrm{AB}$ & $637,1 \mathrm{~A}$ & $236,1 \mathrm{~A}$ \\
Nabo Forrageiro & $99,6 \mathrm{BCD}$ & $92,1 \mathrm{AB}$ & $3046,6 \mathrm{AB}$ & $543,8 \mathrm{~A}$ & $386,3 \mathrm{~A}$ \\
Milheto ADR 500 & $181,8 \mathrm{BCD}$ & $225,4 \mathrm{ABC}$ & $4325,7 \mathrm{~A}$ & $576,3 \mathrm{~A}$ & $472,6 \mathrm{~A}$ \\
Crotalária + Milheto & $219,3 \mathrm{BC}$ & $217,6 \mathrm{AB}$ & $4973,4 \mathrm{AB}$ & $789,0 \mathrm{~A}$ & $448,5 \mathrm{~A}$ \\
Pousio & $259,1 \mathrm{~B}$ & $266,4 \mathrm{~A}$ & $4992,7 \mathrm{AB}$ & $624,6 \mathrm{~A}$ & \\
\hline
\end{tabular}

Para cada ano avaliado, médias seguidas de mesmas letras na coluna, não diferem entre si pelo teste de Tukey, a $5 \%$ de significância.

For each evaluated year, averages followed by the same letters in the column, do not differ by Tukey test, at $5 \%$ of significance.

Os totais de macronutrientes acumulados na parte aérea, na safra 2012/2013, com exceção do $P$, encontram-se um pouco abaixo do reportado por Coelho e França (1995), que para uma produção de $15,3 \mathrm{t} \mathrm{ha}^{-1}$ de $\mathrm{MS}$, o milho acumulou cerca de 181 , 21, 213, 41 e $28 \mathrm{~kg} \mathrm{ha}^{-1}$, respectivamente, de N, P, K, Ca e Mg. No presente estudo, a média acumulada desses nutrientes para uma produtividade média de $14,4 \mathrm{tha} \mathrm{a}^{-1}$ de $\mathrm{MS}$ foi de 153, 28, 177, 17, 18 e $13 \mathrm{~kg} \mathrm{ha}^{-1}$, respectivamente, de N, P, K, Ca, Mg e S. O menor acúmulo de nutrientes encontrado nesse estudo pode ser vantajoso, já que para uma produtividade próxima da encontrada por Coelho e França (1995), o milho reduziu a exigência por alguns nutrientes, podendo então revelar-se mais eficiente na utilização desses nutrientes.

Devido à falta de chuvas, após a semeadura das plantas de cobertura, semeadas em 12 de abril do ano de 2013, não houve germinação das sementes na Fazenda São João, por se tratar de área de sequeiro. Neste ano, portanto, foi avaliado apenas o efeito residual das plantas de cobertura, cultivadas em 2012, na cultura do milho. Na Figura 1, é apresentada a precipitação pluvial da Cidade de Sete Lagoas, localizada a cerca de 30 $\mathrm{km}$ do local experimento. No entanto, mesmo havendo chuvas em Sete Lagoas, no local do experimento, não houve precipitação após a semeadura das plantas.

Os acúmulos totais de nutrientes no milho, nos dois anos de cultivo, foram inferiores aos encontrados por Bender et al. (2013), ao final do ciclo do milho, que reportaram acúmulos entre 286, 49, 168, 59 e $26 \mathrm{~kg}^{\text {ha-1 }}$ de $\mathrm{N}, \mathrm{P}, \mathrm{K}, \mathrm{Mg}$ e S, respectivamente, em condições Norte Americanas. Provavelmente, o menor acúmulo encontrado neste estudo é devido à colheita antecipada do milho para silagem (aproximadamente aos 110 dias após a semeadura), pois, nessa fase, o milho ainda não absorveu a quantidade máxima da maioria dos nutrientes. Além disso, trata-se de híbridos cultivados em ambientes e condições diferentes das encontradas no Brasil. 
Os acúmulos totais de $\mathrm{Cu}, \mathrm{Mn}$ e $\mathrm{Zn}$ foram menores do que os reportados por Borges; Von Pinho e Pereira (2009), para uma produção de 20 t ha $^{-1}$ de MS. Esses autores colheram o milho no estádio fenológico R5 (semelhante ao estádio de coleta desse estudo), o qual acumulou, em média, cerca de 130, 110, 620 e $560 \mathrm{~g} \mathrm{ha}^{-1}$ de B, Cu, Mn e $\mathrm{Zn}$, respectivamente. O menor acúmulo desses nutrientes no presente estudo é devido à menor produção de MS, se comparado ao trabalho de Borges; Von Pinho e Pereira (2009).

Mesmo com uma produção de MS próxima da encontrada por Bender et al. (2013), em cultivares transgênicas, os acúmulos médios de B e Zn foram menores que o demonstrado por esses autores. Já a quantidade média acumulada de Fe, cerca de 3778 $\mathrm{g} \mathrm{ha}^{-1}$, no presente estudo, foi muito superior à encontrada por Bender et al. (2013), que apresentaram acúmulo de aproximadamente $1376 \mathrm{~g} \mathrm{ha}^{-1}$.

\section{CONCLUSÕES}

As plantas de cobertura girassol e milheto apresentaram maior produção de massa seca, e o girassol acumulou a maior quantidade de carbono na parte aérea das plantas. Esse fato é de grande importância em áreas de produção de milho para silagem, principalmente, quando se deseja a reciclagem de carbono e nutrientes nos solos.

Nos dois anos de cultivo, as quantidades totais dos nutrientes acumulados na parte aérea das plantas de milho e a produtividade de massa seca não variaram com as plantas de cobertura, com exceção da quantidade de Fe. Portanto, mesmo obtendo boas produções de massa seca e acúmulo de nutrientes na parte aérea de algumas plantas de cobertura, a reciclagem destas plantas no solo não foi suficiente para interferir, positivamente, nas características analisadas no cultivo das plantas de milho para silagem.

\section{CONTIRBUIÇÃO DOS AUTORES}

Condução do experimento e análise dos dados: Autores GFC e CGMS; Planejamento e coordenação do projeto: Autores SGM e AVR.

\section{CONFLITO DE INTERESSE}

Os autores declararam que não há conflito de interesse.

\section{FINANCIAMENTO}

Os autores reportaram que não receberam suporte ou auxílio financeiro para o desenvolvimento da pesquisa.

\section{REFERÊNCIAS}

ALVARENGA, R.C.; CABEZAS, W.A.L.; CRUZ, J.C.; SANTANA, D.P. Plantas de cobertura de solo para sistema plantio direto. Informe Agropecuário, v.22, n.208, p.25-36, 2001.

BALBINOT JR, A.A.; MORAES, A.; BACKES, R.L. Efeito de coberturas de inverno e sua época de manejo sobre a infestação de plantas daninhas na cultura de milho. Planta Daninha, v.25, n.3, p. 473-480, 2007.

BENDER, R. R.; HAEGELE, J.W.; BELOW, F.E. Nutrient uptake, partitioning, and remobilization in modern, transgenic insect-protected maize hybrids. Agronomy Journal, v.105, n.1, p.161-170, 2013.

BORGES, I. D.; VON PINHO, R. G.; PEREIRA, J. L. A. R. Micronutrients accumulation at different maize development stages. Ciência e Agrotecnologia, v.33, n.4, p.1018-1025, 2009.

BRAZ, A. J.B.P.; SILVEIRA, P.M.; KLIEMANN, H.J.; ZIMMERMANN, F.J.P. Acumulação de nutrientes em folhas de milheto e dos capins braquiária e mombaça. Pesquisa Agropecuária Tropical, v.34, n.2, p.83-87, 2004. 
CARVALHO, M. A. C.; SORATTO, R.P.; ATHAYDE, M.L.F.; ARF, O.; SÁ, M.E. Produtividade do milho em sucessão a adubos verdes no sistema de plantio direto e convencional. Pesquisa Agropecuária Brasileira, v.39, n.1, p.47-53, 2004.

CAZETTA, D. A.; FORNASIERI FILHO, D.; GIROTTO, F. Composição, produção de matéria seca e cobertura do solo emcultivo exclusivo e consorciado de milheto e crotalária. Acta Scientiarum Agronomy, v. 27, n. 4, p. $575-$ 580, 2005.

CERDA, A.; FLANAGAN, D.C., BISSONNAIS, Y., BORDMAN, J. Soil erosion and agriculture. Soil \& Tillage Research, v. 106, n. 1, p. 107-108, 2009.

COELHO, A. M., FRANÇA, G. D. Seja o Doutor do seu Milho. 2. ed. Piracicaba: Potafos, 1995. 25 p.

DERPSCH, R.; CALEGARI, A. Plantas para adubação verde de inverno. Londrina: lapar, 1992. 80p.

DOURADO, M. C.; SILVA, T. R. B.; CÉSAR BOLONHEZI. A. C. matéria seca e produção de grãos de Crotalaria juncea $L$. submetida à poda e adubação fosfatada. Scientia Agricola, v.58, n.2, p.287-293, 2001.

DUARTE, A. P.; KIEHL, J.C.; CAMARGO, M.A.F.; RECO, P.C. Acúmulo de matéria seca e nutrientes em cultivares de milho originárias de clima tropical e introduzidas de clima temperado. Revista Brasileira de Milho e Sorgo, v.2, n.3, p. 1-20, 2003.

FAO. CA Adoption Worldwide: Global Overview of Conservation Agriculture Adoption. 2012. Disponível em: <http://www.fao.org/ag/ca/6c.html>.

FEBRAPDP - Federação Brasileira de Plantio Direto na Palha.Área do sistema plantio direto. Evolução área do sistema plantio direto no brasil, safra 11/12. 2014. Disponível em: http://febrapdp.org.br/area-de-pd.

GUARESCHI, R. F.; GAZOLLA, P.R.; PERIN, A.; ROCHA, A.C. Produção de massa de milho silagem em função do arranjo populacional e adubação. Revista Ciência Agronômica, v.39, n.3, p.468-475, 2008.

MALAVOLTA, E.; VITTI, G.C.; OLIVEIRA, S.A. Avaliação do estado nutricional das plantas: princípios e aplicações. Piracicaba: Associação Brasileira para a Pesquisa da Potassa e do Fosfato, 1997. 319p.

MELERO, S.; LÓPEZ-GARRIDO, R.; MURILLO, J.M.; MORENO, F. Conservation tillage: short- and long-term effects on soil carbon fractions and enzymatic activities under Mediterranean conditions. Soil \& Tillage Research, v. 104, n. 1, p. 292-298, 2009.

MONQUERO, P. A.; CHRISTOFFOLETI, P. J. Banco de sementes de plantas daninhas e herbicidas como fator de seleção. Bragantia, v. 64, n. 2, p. 203-209, 2005.

MOREIRA, S. G.; LUPP, R.M.; LIMA, C.G.; MARUCCI, R.C.; RESENDE, A.V.; BORGES, I.D. Massa seca e macronutrientes acumulados em plantas de milho cultivadas sob diferentes espécies de cobertura. Revista Brasileira de Milho e Sorgo, v.13, n. 2, p. 218-231, 2014.

PACHECO, L. P.; PIRES, F. R.; MONTEIRO, F. P.; PROCÓPIO, S. O.; CARMO, R. L.; PETTER, F. A. Desempenho de plantas de cobertura em sobressemeadura na cultura da soja. Pesquisa Agropecuária Brasileira, v.43, n.7, p.815-823, 2008.

PAULETTI, V. A importância da palhada e da atividade biológica na fertilidade do solo. In: Curso sobre aspectos básicos de fertilidade e microbiologia do solo em plantio direto. 1. ed. Passo Fundo: Aldeia Norte, 1999. p.56-66.

PERIN, A.; SANTOS, R.H.S.; URQUIAGA, S.; GUERRA, J.G.M.; CECON, P.R. Produção de fitomassa, acúmulo de nutrientes e fixação biológica de nitrogênio por adubos verdes em cultivo isolado e consorciado. Pesquisa Agropecuária Brasileira, v.39, n. 1, p.35-40, 2004.

RIBEIRO, A. C.; GUIMARÃES, P. T. G.; ALVAREZ V., V. H. Recomendação para o uso de corretivos e fertilizantes em Minas Gerais: 5. Aproximação. 1. ed. Viçosa: Comissão de Fertilidade do Solo do Estado de Minas Gerais, 1999. 359 p. 
RIZZARDI, M.A.; SILVA, L.F. Influência das coberturas vegetais antecessoras de aveia-preta e nabo forrageiro na época de controle de plantas daninhas em milho. Planta Daninha, v. 24, n. 4, p. 669-675, 2006.

RHEINHEIMER, D. S.; ALVAREZ, J.W.R.; FILHO, B.D.O.; SILVA, L.S.; BORTOLUZZI, E.C. Resposta de culturas à aplicação de enxofre e a teores de sulfato num solo de textura arenosa sob plantio direto. Ciência Rural, v. 35, n. 3, p. 562-569, 2005.

SABUNDJIAN, M. T.; ARF, O.; TARSITANO, M.A.A.; KANEKO, F.H.; CORSINI, D.C.D.C. Análise econômica da adubação nitrogenada em feijoeiro de inverno sob plantio direto. Pesquisa Agropecuária Tropical, v.44, n. 4, p.349-356, 2014.

SILVA, F.C. Manual de análises químicas de solos, plantas e fertilizantes. Brasília: Embrapa Informação Tecnológica, 2009. 627p.

SODRÉ-FILHO, J.; CARDOSO, A.N.; CARMONA, R.; CARVALHO, A.M. Fitomassa e cobertura do solo de culturas de sucessão ao milho na Região do Cerrado. Pesquisa Agropecuária Brasileira, v.39, n. 4, p.327-334, 2004.

SOLDEVILLA-MARTINEZ, M.; MARTIN-LAMMERDING, D.; TENORIO, J.L.; WALTER, I.; QUEMADA, M.; LIZASO, J.I. Simulating improved combination stillage-rotation under dry land conditions. Spanish Journal of Agricultural Research, v.11, n. 3, p.820-832, 2013.

SOUZA, L.S.; VELINI, E.D.; MARTINS, D.; ROSOLEM, C.A. Efeito alelopático de capim-braquiária ( Brachiaria decumbens) sobre o crescimento inicial de sete espécies de plantas cultivadas. Planta Daninha, v. 24, n. 4, p. 657-668, 2006.

TORRES, J.L.R.; PEREIRA, M.G.; FABIAN, A.J. Produção de fitomassa por plantas de cobertura e mineralização de seus resíduos em plantio direto. Pesquisa Agropecuária Brasileira, v.43, n. 3, p.421-428,2008.

VIDAL, R. A.; LAMEGO, F. P.; TREZZI, M. M. Diagnóstico da resistência aos herbicidas em plantas daninhas. Planta Daninha, v. 24, n. 3, p. 597-604, 2006. 